\title{
Association of Normal Body Temperature with Mouth Shape
}

\author{
Muhammad Imran Qadir and Muhammad Kashan Javed* \\ Institute of Molecular Biology and Biotechnology, Baha Uddin Zakariya University, Multan, Pakistan \\ *Corresponding Author: Muhammad Kashan Javed, Institute of Molecular Biology and Biotechnology, Baha Uddin Zakariya University, \\ Multan, Pakistan.
}

Received: July 01, 2019; Published: July 17, 2019

DOI: $10.31080 /$ ASMI.2019.02.0313

\begin{abstract}
The purpose of current survey was to investigate any relation between the normal body temperature with the shape of mouth $\mathrm{Al}$ most 200 individual were contributed in the present survey For the measurement of body temperature, we took digital thermometer and measure the body temperature of every student and mentioned their temperature on the questionnaire. An investigation was set to find any relation between the normal body temperature with the shape of mouth. We come to know from the current survey that the normal body temperature had no scientific relation with the shape of mouth because the p-vale is greater than 0.1 that's why considered as non-significant.
\end{abstract}

Keywords: Association; Temperature; Mouth

\section{Introduction}

The degree of hotness is called temperature of the body. The normal body temperature of human is 98.5 and 37. If the temperature becomes high then the condition referred as fever [1]. Temperature is lower in men than in women and higher in children as compared to adults. Temperature in the body is lower as compared to whole day in the morning [2,3]. Hence if you noticed that your body temperature is higher in the morning than that is very abnormal thing. The instrument which is used for the measurement of body temperature is called thermometer. Digital thermometer also avail in the market which gives you number on the screen of thermometer [4].

Mouth shape is an important factor which plays an important role in the personality of a person. There are various types of mouth shapes such as laughing mouth, sad mouth, Aggressive mouth, crescent mon shaped mouth, Reverse boat out shape, round mouth, square mouth shape, lotus shaped mouth, cherry lips mouth, oval shaped mouth etc. these all mouth shapes have certain or special characteristics like laughing mouth shape is one who seems smile.IN contrast to laughing mouth shape we have sad mouth who seems sad. But here we will focus on oval shaped mouth and round shad mouth [5-9].
The purpose of current survey was to investigate any relation between the normal body temperature with the shape of mouth

\section{Material and Method}

- Almost 200 individuals were contributed in the present survey

- $\quad$ For the measurement of body temperature, we took digital thermometer and measure the body temperature of every student and mentioned their temperature on the questionnaire.

- An investigation was set to find any relation between the normal body temperature with the shape of mouth.

\section{Statistical analysis}

Statistical investigation was done with the help of t-Test and MS-Excel.

\section{Result and Discussion}

Relation of normal temperature of body with the shape of mouth was given in Table 1 . Table 1 clear that there exists no scientific type relationship between the normal body temperature with the shape of mouth because the value of $p$ is greater than 0.1 that's why we said that the result was non- significant. 


\begin{tabular}{|l|l|l|l|}
\hline Gender & $\begin{array}{l}\text { Round shape } \\
\text { mouth }\end{array}$ & Oval shape mouth & $\boldsymbol{p}$-Value \\
\hline Male & $97.25 \pm 2.37$ & $82.15 \pm 35.71$ & 0.26 \\
\hline Female & $96.67 \pm 1.96$ & $97.041 \pm .59$ & 0.30 \\
\hline Combined & $96.92 \pm 0.45$ & $89.59 \pm 10.52$ & 0.23 \\
\hline
\end{tabular}

Table 1: Regular Body Temperature Association with the shape of Mouth (Mean \pm SD).

( $p>0.1$ hence $p$ considered as non-significant)

An investigation was set to find any relation of normal body temperature with the shape of mouth.

\section{Conclusion}

We come to know from the current survey that the normal body temperature had no scientific relation with the shape of mouth because the $\mathrm{p}$-vale is greater than 0.1 that's why considered as non-significant.

\section{Bibliography}

1. Reith J., et al. "Body temperature in acute stroke: relation to stroke severity, infarct size, mortality, and outcome". The Lancet 347 (1996): 422-425.

2. Refinetti $\mathrm{R}$ and Menaker M. "The circadian rhythm of body temperature”. Physiology and behaviour 51 (1992): 613-637.

3. Qadir MI and Saleem A. "Awareness about ischemic heart disease in university biotechnology students". Global Advanced Research Journals 7.3 (2018): 059-061.

4. Qadir MI and Ishfaq S. "Awareness about hypertension in biology students". International Journal of Pharmaceutical Research 7 (2018): 08-10.

5. Qadir MI and Mehwish. "Awareness about psoriasis disease". International Journal of Pharmaceutical Research 7 (2018): 17-18.

6. Qadir MI and Shahzad R. "Awareness about obesity in postgraduate students of biotechnology". International Journal of Pharmaceutical Research 7 (2018): 14-16.

7. Qadir MI and Rizvi M. "Awareness about thalassemia in post graduate students". MOJ Lymphology and Phlebology 2 (2018): 14-16.
8. Qadir MI and Ghalia BA. "Awareness survey about colorectal cancer in students of M. Phil Biotechnology at Bahauddin Zakariya University, Multan, Pakistan". NACS 1 (2018).

9. Qadir MI and Saba G. "Awareness about intestinal cancer in university student". NACS 1 (2018).

\section{Volume 2 Issue 8 August 2019}

(C) All rights are reserved by Muhammad Imran Qadir and Muhammad Kashan Javed. 